Chronic Obstructive Pulmonary Diseases:

Journal of the COPD Foundation

\author{
Original Research
}

\title{
Progression of Emphysema and Small Airways Disease in Cigarette Smokers
}

\author{
Esther Pompe, MD, $\mathrm{PhD}^{1}$ Camille M. Moore, $\mathrm{PhD}^{2}$ Firdaus A.A. Mohamed Hoesein, $\mathrm{MD}, \mathrm{PhD}$
}

Pim A. de Jong, MD, $\mathrm{PhD}^{3}$ Jean-Paul Charbonnier, $\mathrm{PhD}^{4}$ MeiLan K. Han, $\mathrm{MD}^{5}$ Steven M. Humphries, $\mathrm{PhD}^{6}$

Charles R. Hatt, $\mathrm{PhD}^{7}$ Craig J. Galbán, $\mathrm{PhD}^{8,9} \mathrm{Ed} \mathrm{K}$. Silverman, MD, PhD ${ }^{10,11}$ James D. Crapo, $\mathrm{MD}^{12}$

George R. Washko, MD, PhD ${ }^{11}$ Elisabeth A. Regan, MD, PhD ${ }^{13}$ Barry Make, $\mathrm{MD}^{12}$ Matthew Strand, $\mathrm{PhD}^{2}$

Jan-Willem J. Lammers, MD, $\mathrm{PhD}^{1}$ Eva M. van Rikxoort, $\mathrm{PhD}^{4}$ David A. Lynch, $\mathrm{MD}^{6}$ on behalf of the COPDGene ${ }^{\circledR}$ investigators

\begin{abstract}
Background: Little is known about factors associated with emphysema progression in cigarette smokers. We evaluated factors associated with change in emphysema and forced expiratory volume in 1 second $\left(F E V_{1}\right)$ in participants with and without chronic obstructive pulmonary disease (COPD).

Methods: This retrospective study included individuals participating in the COPD Genetic Epidemiology study who completed the 5-year follow-up, including inspiratory and expiratory computed tomography (CT) and spirometry. All paired CT scans were analyzed using micro-mapping, which classifies individual voxels as emphysema or functional small airway disease (fSAD). Presence and progression of emphysema and FEV 1 were determined based on comparison to nonsmoker values. Logistic regression analyses were used to identify clinical parameters associated with disease progression.

Results: A total of 3088 participants were included with a mean $\pm S D$ age of $60.7 \pm 8.9$ years, including 72 nonsmokers. In all Global initiative for chronic Obstructive Lung Disease (GOLD) stages, the presence of emphysema at baseline was associated with emphysema progression (odds ratio [OR]: GOLD 0: 4.32; preserved ratio-impaired spirometry [PRISm]; 5.73; GOLD 1: 5.16; GOLD 2: 5.69; GOLD 3/4: 5.55; all $p \leq 0.01$ ). If there was no emphysema at baseline, the amount of $\mathrm{ASAD}$ at baseline was associated with emphysema progression (OR for 1\% increase: GOLD 0: 1.06; PRISm: 1.20; GOLD 1: 1.7; GOLD 3/4: 1.08; all $p \leq 0.03)$. In 1735 participants without spirometric COPD, progression in emphysema occurred in 105 (6.1\%) participants and only 21 (1.2\%) had progression in both emphysema and $\mathrm{FEV}_{1}$.

Conclusions: The presence of emphysema is an important predictor of emphysema progression. In patients without emphysema, fSAD is associated with the development of emphysema. In participants without spirometric $\mathrm{COPD}$, emphysema progression occurred independently of $\mathrm{FEV} 1$ decline.
\end{abstract}

\footnotetext{
Abbreviations: forced expiratory volume in 1 second, FEV1; chronic obstructive pulmonary disease, COPD; computed tomography, CT; functional small airways disease, fSAD; Global initiative for chronic Obstructive Lung Disease, GOLD; odds ratio, OR; preserved ratio- impaired spirometry, PRISm; St George's Respiratory Questionnaire, SGRQ; 6-minute walking distance, 6MWD; modified Medical Research Council dyspnea score, mMRC; total lung capacity, TLC; Hounsfield unit, HU; functional residual capacity, FRC

Funding Support: The project described was supported by grants R01HL089897 and R01HL089856 from the National Heart, Lung, and Blood Institute. The COPD Genetic Epidemiology (COPDGene ${ }^{\circledast}$ ) study is also supported by the COPD Foundation through contributions made to an industry advisory board representing AstraZeneca, Boehringer Ingelheim, Novartis, Pfizer, Siemens, Sunovion, and GlaxoSmithKline. In addition, this project has been financially supported by the Foundation "De Drie Lichten" in the Netherlands, the Lung Foundation Netherlands (grant 9.1.15.067FE), and the Foundation "Stichting Astma Bestrijding."
} 
Date of Acceptance: November 19, 2020 | Published Online Date: December 2, 2020

Citation: Pompe E, Moore CM, Mohamed Hoesein FAA, et al for the COPDGene Investigators. Progression of emphysema and small airways disease in cigarette smokers. Chronic Obstr Pulm Dis. 202 1;8(2):198-212. doi: https://doi.org/10.15326/jcopdf.2020.0140

1 Imaging Department, University Medical Center Utrecht, Utrecht, the Netherlands

2 Division of Biostatistics, Environment and Health, National Jewish Health, Denver, Colorado, United States

3 Department of Radiology, University Medical Center Utrecht, Utrecht, the Netherlands

4 Diagnostic Image Analysis Group, Radboud University Medical Center, Nijmegen, the Netherlands

5 Division of Pulmonary and Critical Care, University of Michigan Health System, Ann Arbor, Michigan, United States

6 Department of Radiology, National Jewish Health, Denver, Colorado, United States

7 Imbio LLC, Minneapolis, Minnesota, United States

8 Department of Radiology, University of Michigan, Ann Arbor, Michigan, United States

9 Center for Molecular Imaging, University of Michigan, Ann Arbor, Michigan, United States

10 Channing Division of Network Medicine, Brigham and Women's Hospital, Boston, Massachusetts, United States

11 Division of Pulmonary and Critical Care Medicine, Department of Medicine, Brigham and Women's Hospital, Boston,

Massachusetts, United States

12 Division of Pulmonary, Critical Care and Sleep Medicine, Department of Medicine, National Jewish Health, Denver, Colorado, United States

13 Division of Rheumatology, Department of Medicine, National Jewish Health, Denver, Colorado, United States

\section{Address correspondence to:}

Esther Pompe, MD

Imaging Department

University Medical Center

UtrechtPostbus 85500

3508 GA Utrecht

Postbox: E.03.511

E-mail: e.pompe@umcutrecht.nl

Phone: +31 887550846

\section{Keywords:}

computed tomography; emphysema; air trapping; COPD;

functional small airways disease

\section{This article contains an online supplement.}

\section{Introduction}

Cigarette smoking remains common around the world and is responsible for a wide range of diseases including chronic obstructive pulmonary disease (COPD). After 25 years of smoking, only a minority of individuals will develop COPD by spirometric criteria, ${ }^{1}$ but the spirometric diagnosis of COPD likely underestimates the burden of this smokingrelated lung disease. Indeed, it has been shown that more than half of current and former smokers who do not meet the spirometric criteria for COPD have emphysema and may have significant respiratory symptoms. ${ }^{2,3}$

Smoking cessation alone does not eliminate lung disease, and smoking-related abnormalities may still progress after smoking cessation. Identification of individuals at risk for progression is, therefore, of great importance since early intervention and treatment may prevent clinical deterioration. Computed tomography (CT) quantification techniques could be valuable in the identification of the presence and progression of smoking-related changes in the airways and the lungs, as they can provide information that would amplify and augment spirometric data. ${ }^{4-6}$

The associations between changes in forced expiratory volume in 1 second $\left(F E V_{1}\right)$ and baseline CT-derived emphysema and functional small airway disease (FSAD) have been evaluated in individuals with early disease and showed that FSAD at baseline is associated with $\mathrm{FEV}_{1}$ decline over time. ${ }^{6,7}$ This could mean that airway disease precedes lung function decline and is in keeping with the hypothesis that airway loss and obstruction are precursors of emphysema. Indeed, in a more recent study, it has been shown that $\mathrm{SSAD}$ seems to be a radiologic precursor of progression in emphysema. ${ }^{7}$ However, how this relates to changes in lung function remains unknown. Also, results on the relationship between other clinical parameters such as the St George's Respiratory Questionnaire (SGRQ) and the 6-minute walking distance (6MWD) and emphysema progression are lacking. Yet, it is important to determine how quantitative CT parameters of emphysema and fSAD progress over time and to assess their relationship to changes in clinical parameters and $\mathrm{FEV}_{1}$.

The main objective of this study was to determine factors that contribute to progression of emphysema and FEV 1 . To accomplish this, 5-year follow-up data from the large multi-center COPD Genetic Epidemiology (COPDGene@) study was used and baseline clinical and CT imaging variables were 
evaluated for their association with emphysema and $F E V_{1}$. A primary focus was to identify factors associated with disease progression in individuals with little or no airflow obstruction at baseline.

\section{Methods}

\section{Participants}

Participants for this study were participants in the COPDGene study. ${ }^{8}$ This multicenter observational cohort study included current and former smokers with or without airflow obstruction and a smoking history of $\geq 10$ pack years. In addition, healthy nonsmokers with a lifetime smoking history of $<100$ cigarettes, no history of lung disease, and normal post-bronchodilator spirometry were recruited.

In the present study, we examined the first 5000 COPDGene participants who returned for 5-year follow-up visits. A total of 40 participants were nonsmokers. An additional 32 nonsmokers who returned for their follow-up were added to increase the amount of nonsmoking data. The total number of participants was reduced to 3088 after exclusion of participants because of several reasons as shown in the consort diagram (Figure $S 1$ in the online supplement). Two nonsmoking participants were excluded as scanner calibrations differed from the rest of the nonsmokers. Longitudinal spirometry data was missing in 44 participants, but data on emphysema progression was present. The COPDGene study was approved by the institutional review board at each center, and all participants provided written informed consent.

\section{Pulmonary Function Tests}

All participants underwent pre- and postbronchodilator spirometry. Post-bronchodilator spirometry was performed (ndd Easy-One spirometer, Andover, Massachusetts) and airflow obstruction (i.e., diagnosis of COPD) was defined by a postbronchodilator $F E V_{1} / F V C<0.70$ according to the Global initiative for chronic Obstructive Lung Disease (GOLD) guidelines and disease severity was defined by GOLD stage. ${ }^{9}$ Participants with $\mathrm{FEV}_{1} / \mathrm{FVC} \geq 0.70$, but with $\mathrm{FEV}_{1} \%$ predicted $<80 \%$ were considered to have preserved ratio-impaired spirometry (PRISm). ${ }^{10}$

\section{Clinical Parameters}

Data on smoking history was recorded at baseline and follow-up by using standard questionnaires. ${ }^{8}$ Additionally, respiratory quality of life was assessed using the SGRQ. ${ }^{11}$ The modified Medical Research Council (mMRC) dyspnea score, ${ }^{12}$ and 6MWD were also assessed.

\section{Computed Tomography-Acquisition and Micro-mapping}

All participants underwent paired inspiratory and expiratory $\mathrm{CT}$ scans at maximal inspiration (total lung capacity [TLC]) and end-expiration using a standardized protocol. 8 The lungs were segmented automatically using Thirona Lung Quantification software (Nijmegen, the Netherlands) and segmentations were visually checked. ${ }^{13}$ The micromapping technique was applied using a technique similar to parametric response mapping described by Galbán et al. ${ }^{14,15}$ In brief, the inspiratory and expiratory CT scans were spatially co-registered, after which, voxels were classified based on their inspiratory and expiratory Hounsfield unit (HU). ${ }^{14}$ All voxels <-950HU on inspiratory CT and <-856HU on expiratory CT were classified as emphysematous; voxels between $-950 \mathrm{HU}$ and $-500 \mathrm{HU}$ on inspiratory $\mathrm{CT}$ and $<-856 \mathrm{HU}$ on expiratory CT were classified as fSAD; voxels between $-950 \mathrm{HU}$ and $-500 \mathrm{HU}$ on inspiratory CT and between -856 and $-500 \mathrm{HU}$ on expiratory CT were classified as normal lung tissue. Voxels below $-950 \mathrm{HU}$ on inspiratory CT, but above -856HU in the expiratory CT were classified as "other." The number of voxels per category were expressed as a percentage of all classified voxels to achieve relative lung volumes.

\section{Statistical Analysis}

A linear mixed model was created for log (emphysema) as a function of age, gender, race, body mass index (BMI), smoking status, pack years, functional residual capacity (FRC)/TLC derived from CT, and observation time. Additionally, the interaction between observation time and clinical variables was included to evaluate differences between participants in progression over time. Random intercepts were included for each participant, study center, and scanner make/model to account for correlation due to repeated measurements on participants over time, clustering of participants in study centers, and the effect of different CT scanner models. Similar models were created for $\log \left(F E V_{1}\right)$ (not including $F R C$ / 
TLC derived from CT and the effect of different CT scanner models).

Logistic regression models were used to test associations between baseline characteristics and the odds of emphysema progression. Participants were defined as "progressing" if their emphysema and/or FEV 1 changed beyond the 95th percentile of change observed in nonsmokers (0.25\% emphysema progression per year; $89 \mathrm{~mL}$ decrease in $\mathrm{FEV}_{1}$ per year). Similarly, the presence of baseline emphysema was defined as having more than the 95th percentile in nonsmokers (>1.31\%). Generalized estimating equations were used to account for clustering of participants in study centers. A baseline model was created using clinical characteristics (age, gender, race, BMI, smoking status, and pack years) after which the presence of baseline emphysema, the amount of $\mathrm{fSAD}, 6 \mathrm{MWD}, \mathrm{SGRQ}$, and the presence of self-reported exacerbations at baseline were added to the model separately. An additional model was created including an interaction between fSAD and the presence of baseline emphysema to evaluate the association of FSAD and emphysema progression in the absence of baseline emphysema. Analyses were stratified by GOLD stage. A similar set of models was fit using FEV 1 progression as the outcome. Sensitivity analyses were performed using cut-off values at the 90th and 97.5th percentile (cut-off values of $0.14 \%$ and $0.45 \%$ emphysema per year, and $76 \mathrm{~mL}$ and $100 \mathrm{~mL}$ in $\mathrm{FEV}_{1}$ per year, respectively). In addition, since a change of $76 \mathrm{~mL}$ in $\mathrm{FEV}_{1}$ per year is still quite high, we performed 2 additional sensitivity analyses. Multivariate logistic regression models for $F E V_{1}$ were created where $F E V_{1}$ progression (yes/no) was defined as a decline in $\mathrm{FEV}_{1}$ of greater than $2 \%$ or $4 \%$ per year, resulting in declines of approximately $10 \%$ or $20 \%$ from baseline over the typical 5-year follow-up.

The percentage of voxels that shifted from one category to another, at follow-up as compared to baseline, were evaluated separately for participants who progressed and participants who did not progress. $P$-values of $<0.05$ were considered statistically significant. As presented, $p$-values are not adjusted for multiple comparisons (more than 40 statistical tests were performed). Analyses were performed using SPSS 23.0 (Chicago, Illinois) and R 3.2.3 (the R Foundation, Vienna, Austria).

\section{Results}

Of 3088 included participants, 72 (2.3\%) participants were nonsmokers, 1430 (46.3\%) were classified as GOLD 0, 305 (9.9\%) as PRISm, 267 (8.6\%) as GOLD 1, 616 (19.9\%) as GOLD 2, 332 (10.8\%) as GOLD 3, and 66 (2.1\%) as GOLD 4, based on Phase-1 spirometry. In further analyses, GOLD 3 and GOLD 4 are grouped together (total 398 participants). Mean \pm SD follow-up time was $5.3 \pm 0.5$ years for current/former smokers and $5.5 \pm 0.8$ years for nonsmokers. Baseline characteristics are shown

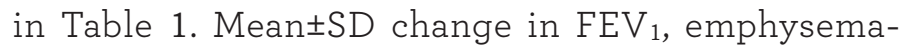
like voxels, and $\mathrm{ASAD}$ per year in nonsmokers was $-31 \pm 29 \mathrm{ml}, 0.003 \pm 0.13 \%$, and $0.08 \pm 0.76 \%$, respectively. Overall change in emphysema, fSAD, and $F E V_{1}$ beyond nonsmokers is shown in Figure 1. Figure 2 is stratified by GOLD stage and shows results for emphysema and $F E V_{1}$. Change in $\mathrm{FSAD}$ is shown in Figure S2 in the online supplement and results for the PRISm group are shown in Figure S3 in the online supplement. Baseline characteristics stratified by progression group are shown in Table S 1 in the online supplement.

\section{GOLD 0}

In GOLD 0 participants, the median (25th-75th percentile) percentage of emphysema at baseline was $0.3 \%$ (0.1-1.0). Median (25th-75th percentile) change in emphysema per year was 0.0\% (-0.050.03). Complete results of longitudinal multivariate analyses with emphysema and $\mathrm{FEV}_{1}$ as outcome are shown in Table S2 and Table S3 in the online supplement. Male gender and lower BMI were associated with larger increases in emphysema ( $p=0.004$ and $p<0.001$, respectively).

Progression in emphysema (compared with nonsmokers) occurred in 89/1430 (6.2\%) participants; decrease in $\mathrm{FEV}_{1}$ occurred in 186 (13.0\%); and progression in emphysema and decrease in FEV 1 occurred in 19 (1.3\%) participants. The number of participants who progressed is shown in Table 2. An example of a CT-scan of a GOLD 0 participant progressing in emphysema is shown in Figure 3.

Generalized estimating equation models showed that the presence of emphysema at baseline increased the odds of progressing in emphysema (odds ratio [OR]:4.32, 95\% CI 2.30 to 8.14) (Figure 4). Baseline fSAD was associated with emphysema progression as 


\section{Table 1. Baseline Characteristics, Stratified by GOLD Spirometry Grade and Expressed as Medians $\left(25^{\text {th }}-75^{\text {th }}\right.$ Percentile) or Means (Standard Deviation)}

\begin{tabular}{|c|c|c|c|c|c|c|c|}
\hline Variable & $\begin{array}{c}\text { Nonsmokers } \\
(n=72)\end{array}$ & $\begin{array}{l}\text { GOLD } 0 \\
(n=1430)\end{array}$ & $\begin{array}{l}\text { PRISm } \\
(n=305)\end{array}$ & $\begin{array}{l}\text { GOLD } 1 \\
(n=267)\end{array}$ & $\begin{array}{l}\text { GOLD } 2 \\
(n=616)\end{array}$ & $\begin{array}{l}\text { GOLD } 3 \\
(n=332)\end{array}$ & $\begin{array}{l}\text { GOLD } 4 \\
(n=66)\end{array}$ \\
\hline Age, years & $\begin{array}{r}62.3 \\
(53.4-67.9)\end{array}$ & $\begin{array}{r}58.0 \\
(51.3-64.9)\end{array}$ & $\begin{array}{r}57.8 \\
(52.0-64.3)\end{array}$ & $\begin{array}{r}62.5 \\
(56.7-69.2)\end{array}$ & $\begin{array}{r}63.0 \\
(57.2-69.1)\end{array}$ & $\begin{array}{r}63.6 \\
(58.3-70.0)\end{array}$ & $\begin{array}{r}64.0 \\
(59.9-68.5)\end{array}$ \\
\hline Male, n(\%) & $\begin{array}{r}23 \\
(31.9 \%)\end{array}$ & $\begin{array}{r}686 \\
(48.0 \%)\end{array}$ & $\begin{array}{r}138 \\
(45.2 \%)\end{array}$ & $\begin{array}{r}148 \\
(55.4 \%)\end{array}$ & $\begin{array}{r}336 \\
(54.5 \%)\end{array}$ & $\begin{array}{r}187 \\
(56.3 \%)\end{array}$ & $\begin{array}{r}36 \\
(54.5 \%)\end{array}$ \\
\hline White, $n(\%)$ & $\begin{array}{r}67 \\
(93.1 \%)\end{array}$ & $\begin{array}{r}1078 \\
(75.4 \%)\end{array}$ & $\begin{array}{r}217 \\
(71.1 \%)\end{array}$ & $\begin{array}{r}226 \\
(84.6 \%)\end{array}$ & $\begin{array}{r}496 \\
(80.5 \%)\end{array}$ & $\begin{array}{r}270 \\
(81.3 \%)\end{array}$ & $\begin{array}{r}63 \\
(95.5 \%)\end{array}$ \\
\hline $\begin{array}{l}\text { Current Smoker, } \\
\mathrm{n}(\%)\end{array}$ & $\begin{array}{r}0 \\
(0 \%) \\
\end{array}$ & $\begin{array}{r}635 \\
(44.4 \%) \\
\end{array}$ & $\begin{array}{r}152 \\
(49.8 \%) \\
\end{array}$ & $\begin{array}{r}123 \\
(46.1 \%) \\
\end{array}$ & $\begin{array}{r}272 \\
(44.2 \%) \\
\end{array}$ & $\begin{array}{r}114 \\
(34.3 \%) \\
\end{array}$ & $(18.2 \%)$ \\
\hline BMI, $\mathrm{kg} / \mathrm{cm}^{2}$ & $\begin{array}{r}27.5 \\
(24.5-31.3) \\
\end{array}$ & $\begin{array}{r}28.4 \\
(25.2-32.4) \\
\end{array}$ & $\begin{array}{r}31.2 \\
(27.7-37.0) \\
\end{array}$ & $\begin{array}{r}26.3 \\
(23.8-30.3) \\
\end{array}$ & $\begin{array}{r}27.9 \\
(24.6-31.9) \\
\end{array}$ & $\begin{array}{r}27.3 \\
(24.0-31.6) \\
\end{array}$ & $\begin{array}{r}26.6 \\
(22.1-29.1) \\
\end{array}$ \\
\hline Pack Years & 0 & $\begin{array}{r}34.2 \\
(22.0-45.9)\end{array}$ & $\begin{array}{r}37.4 \\
(27.9-50.4)\end{array}$ & $\begin{array}{r}41.0 \\
(30.0-56.9)\end{array}$ & $\begin{array}{r}45.0 \\
(34.0-61.8)\end{array}$ & $\begin{array}{r}49.5 \\
(37.0-70.5)\end{array}$ & $\begin{array}{r}48.0 \\
(39.0-72.7)\end{array}$ \\
\hline $\mathbf{F E V}_{\mathbf{1}}, \mathrm{L}$ & $\begin{array}{r}2.8 \\
(2.4-3.8)\end{array}$ & $\begin{array}{r}2.8 \\
(2.4-3.3)\end{array}$ & $\begin{array}{r}2.1 \\
(1.7-2.5)\end{array}$ & $\begin{array}{r}2.6 \\
(2.1-3.1)\end{array}$ & $\begin{array}{r}1.9 \\
(1.6-2.3)\end{array}$ & $\begin{array}{r}1.1 \\
(1.0-1.4)\end{array}$ & $\begin{array}{r}0.7 \\
(0.6-0.8)\end{array}$ \\
\hline SGRQ score & $\begin{array}{r}0 \\
(0-2.6)\end{array}$ & $\begin{array}{r}7.9 \\
(2.4-19.9)\end{array}$ & $\begin{array}{r}19.4 \\
(6.2-38.8)\end{array}$ & $\begin{array}{r}11.5 \\
(3.8-24.6)\end{array}$ & $\begin{array}{r}25.9 \\
(11.6-44.3)\end{array}$ & $\begin{array}{r}40.1 \\
(25.9-55.0)\end{array}$ & $\begin{array}{r}48.2 \\
(34.7-60.6)\end{array}$ \\
\hline mMRC score & $0 \pm 0.2$ & $0.6 \pm 1.1$ & $1.3 \pm 1.4$ & $0.7 \pm 1.1$ & $1.4 \pm 1.3$ & $2.2 \pm 1.3$ & $2.8 \pm 1.0$ \\
\hline 6MWD, m & $\begin{array}{r}529.4 \\
73.0-598.6)\end{array}$ & $\begin{array}{r}487.7 \\
(419.1-548.6)\end{array}$ & $\begin{array}{r}426.7 \\
(353.6-484.9)\end{array}$ & $\begin{array}{r}482.5 \\
(420.0-541.0)\end{array}$ & $\begin{array}{r}431.3 \\
366.1-498.3)\end{array}$ & $\begin{array}{r}374.9 \\
(299.9-442.0)\end{array}$ & $\begin{array}{r}351.7 \\
(272.8-392.0)\end{array}$ \\
\hline $\begin{array}{l}\text { Exacerbations in } \\
\text { the Past Year, } n(\%)\end{array}$ & $\begin{array}{r}3 \\
(4.2 \%)\end{array}$ & $\begin{array}{r}121 \\
(8.5 \%)\end{array}$ & $\begin{array}{r}64 \\
(21.0 \%)\end{array}$ & $\begin{array}{r}29 \\
(10.9 \%)\end{array}$ & $\begin{array}{r}153 \\
(24.8 \%)\end{array}$ & $\begin{array}{r}126 \\
(38.0 \%)\end{array}$ & (56.1\%) \\
\hline $\begin{array}{l}\text { Emphysema, \% of } \\
\text { lung volume }\end{array}$ & $\begin{array}{r}0.2 \\
(0.0-0.4)^{a}\end{array}$ & $\begin{array}{r}0.3 \\
(0.1-1.0)\end{array}$ & $\begin{array}{r}0.2 \\
(0.1-0.7)\end{array}$ & $\begin{array}{r}1.7 \\
(0.5-4.5)\end{array}$ & $\begin{array}{r}2.9 \\
(0.8-8.4)\end{array}$ & $\begin{array}{r}12.5 \\
(4.2-22.7)\end{array}$ & $\begin{array}{r}27.1 \\
(15.9-38.1)\end{array}$ \\
\hline $\begin{array}{l}\text { fSAD, \% of lung } \\
\text { volume }\end{array}$ & $\begin{array}{r}6.5 \\
(4.4-10.0)^{\mathrm{a}}\end{array}$ & $\begin{array}{r}8.4 \\
(5.7-12.7)\end{array}$ & $\begin{array}{r}8.3 \\
(5.0-12.4)\end{array}$ & $\begin{array}{r}16.5 \\
(9.7-23.3)\end{array}$ & $\begin{array}{r}21.0 \\
(13.4-29.4)\end{array}$ & $\begin{array}{r}34.6 \\
(25.7-40.6)\end{array}$ & $\begin{array}{r}37.6 \\
(31.0-43.0)\end{array}$ \\
\hline
\end{tabular}

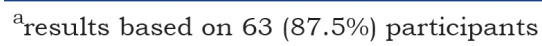

GOLD $=$ Global initiative for chronic Obstructive Pulmonary Disease; PRISm=preserved ratio-impaired spirometry $(\mathrm{FEV} 1<80 \%$ and $\mathrm{FEV}_{1} / \mathrm{FVC} \geq 0.7$ ); $\mathrm{BMI}=$ body mass index; $\mathrm{FEV}_{1}=$ forced expiratory volume in 1 second; SGRQ=St George's Respiratory Questionnaire; $\mathrm{mMRC}=$ modified Medical Research Council; $6 \mathrm{MWD}=6$-minute walking distance; $\mathrm{fSAD}=$ functional small airway disease

well (OR for 1\% increase: $1.06,95 \%$ CI 1.04 to 1.09 ). fSAD did not associate with emphysema progression for participants with emphysema at baseline (OR for $1 \%$ increase: $1.02,95 \%$ CI 0.99 to 1.04 ). However, in the absence of baseline emphysema, fSAD did associate with emphysema progression (OR for 1\% increase: $1.04,95 \%$ CI 1.00 to 1.09 ) (Figure 5). Other clinical predictors of emphysema progression were lower 6MWD (OR for 100m increase: 0.99, 95\% CI 0.99 to 0.99), higher SGRQ (OR for 1-unit increase: 1.02 , 95\% CI 1.00 to 1.03 ), higher $\mathrm{mMRC}$ (OR for 1-unit increase: $1.26,95 \%$ CI 1.01 to 1.56 ), and the presence of exacerbations in the past year (OR:1.98, $95 \%$ CI 1.32 to 2.96 ). The only baseline predictor of a decrease in FEV 1 was SGRQ (OR for 1-unit increase: $1.01,95 \%$ CI 1.01 to 1.02 ). Complete results are shown in Table S4 and Table S5 in the online supplement.

\section{PRISm}

In PRISm participants, the median (25th-75th percentile) percentage of emphysema at baseline was $0.2 \%$ (0.1-0.7). Median (25th-75th percentile) change in emphysema per year was 0.0\% (-0.02-0.04). Higher age and white race were associated with a 


\section{Figure 1. Graph Showing the Number of Progressors in (A) Emphysema, (B) Functional Small Airway Disease, and (C) Forced Expiratory Volume in 1 Second in All Smoking Participants ${ }^{a}$}
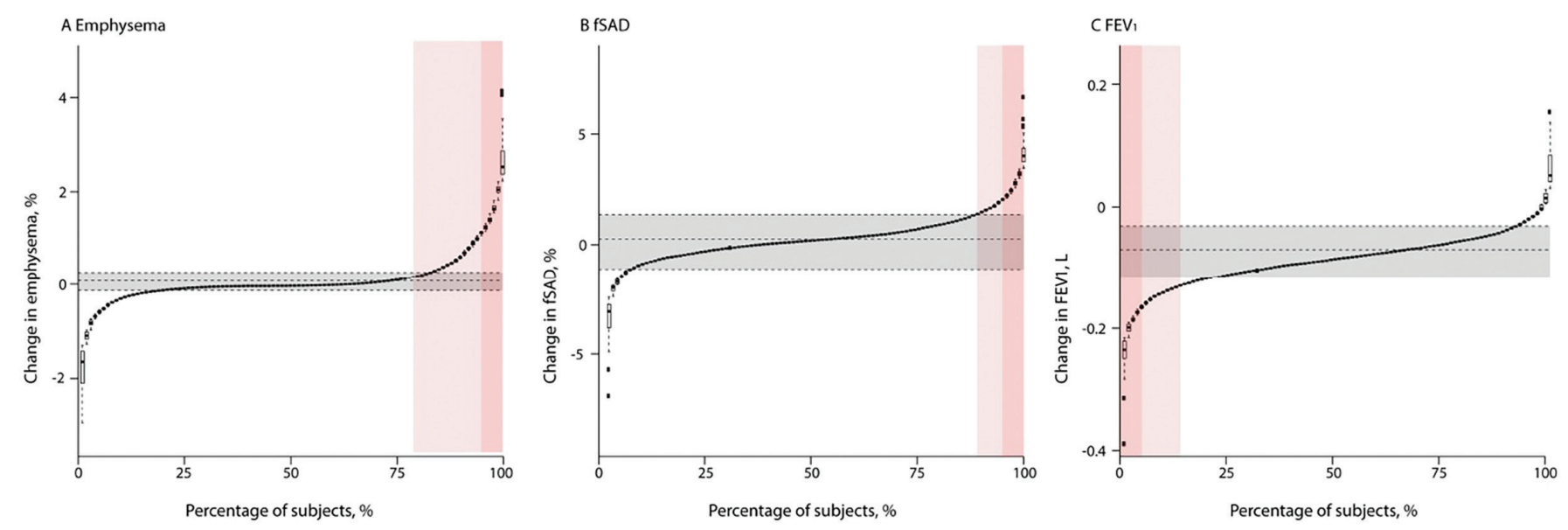

${ }^{a}$ current and former smokers; $\mathrm{n}=3016$

The gray area depicts the 5 th to 95 th percentile of change in nonsmokers $(n=72)$. The dark pink area denotes $5 \%$ of participants who have the biggest change. The light pink area denotes all participants who change more than nonsmokers.

higher increase in emphysema over time ( $p=0.04$ and $p=0.04$, respectively).

Progression in emphysema occurred in 16/1430 (5.2\%) participants; decrease in FEV 1 occurred in 22 (7.2\%); progression in emphysema and $\mathrm{FEV}_{1}$ occurred in $2(0.7 \%)$. The number of emphysema progressors and participants decreasing in $\mathrm{FEV}_{1}$ did not allow for multivariate comparisons. In the sensitivity analyses where a cut-off at the 90th percentile was used, multivariate analyses were possible with 40 (13.1\%) participants progressing in emphysema. This model showed that the presence of emphysema at baseline was associated with emphysema progression (OR:5.73, 95\% CI 1.98 to 16.61). fSAD at baseline was significantly associated with emphysema progression as well (OR:1.11, 95\% CI 1.05 to 1.18). For participants with emphysema at baseline, fSAD was not associated with emphysema progression (OR for $1 \%$ increase: $0.98,95 \%$ CI 0.88 to 1.10$)$. In the absence of baseline emphysema, fSAD did associate with emphysema progression (OR for 1\% increase: $1.20,95 \%$ CI 1.05 to 1.38). Another clinical predictor of emphysema progression in PRISm participants was the presence of exacerbations in the past year (OR:1.75, 95\% CI 1.06 to 2.87).

\section{GOLD 1}

In GOLD 1 participants, the median (25th-75th percentile) percentage of emphysema at baseline was $1.7 \%$ (0.5-4.5). Median (25th-75th percentile) change in emphysema per year was 0.02\% (-1.13-0.21). Changes in emphysema over time did not significantly differ by the demographic factors included in the model.

Progression in emphysema (compared with nonsmokers) occurred in 61/1430 (22.8\%) participants; decrease in $\mathrm{FEV}_{1}$ occurred in 50 (18.7\%); progression in emphysema and decrease in $\mathrm{FEV}_{1}$ occurred in 17 (6.4\%) participants. The presence of emphysema at baseline associated with emphysema progression (OR:5.16, 95\% CI 2.89 to 9.22). fSAD at baseline associated with emphysema progression as well (OR:1.06, 95\% CI 1.03 to 1.10 ). Similar to GOLD 0, for participants with emphysema at baseline, fSAD was not significantly associated with emphysema progression (OR for 1\% increase: $0.99,95 \%$ CI 0.94 to 1.04 ), but in the absence of baseline emphysema, fSAD did associate with emphysema progression (OR for $1 \%$ increase: 1.16 , 95\% CI 1.07 to 1.25$)$. Other clinical predictors of 


\section{Figure 2. Number of Progressors in Emphysema and Forced Expiratory Volume in 1 Second, Stratified by GOLD Spirometry Grade}
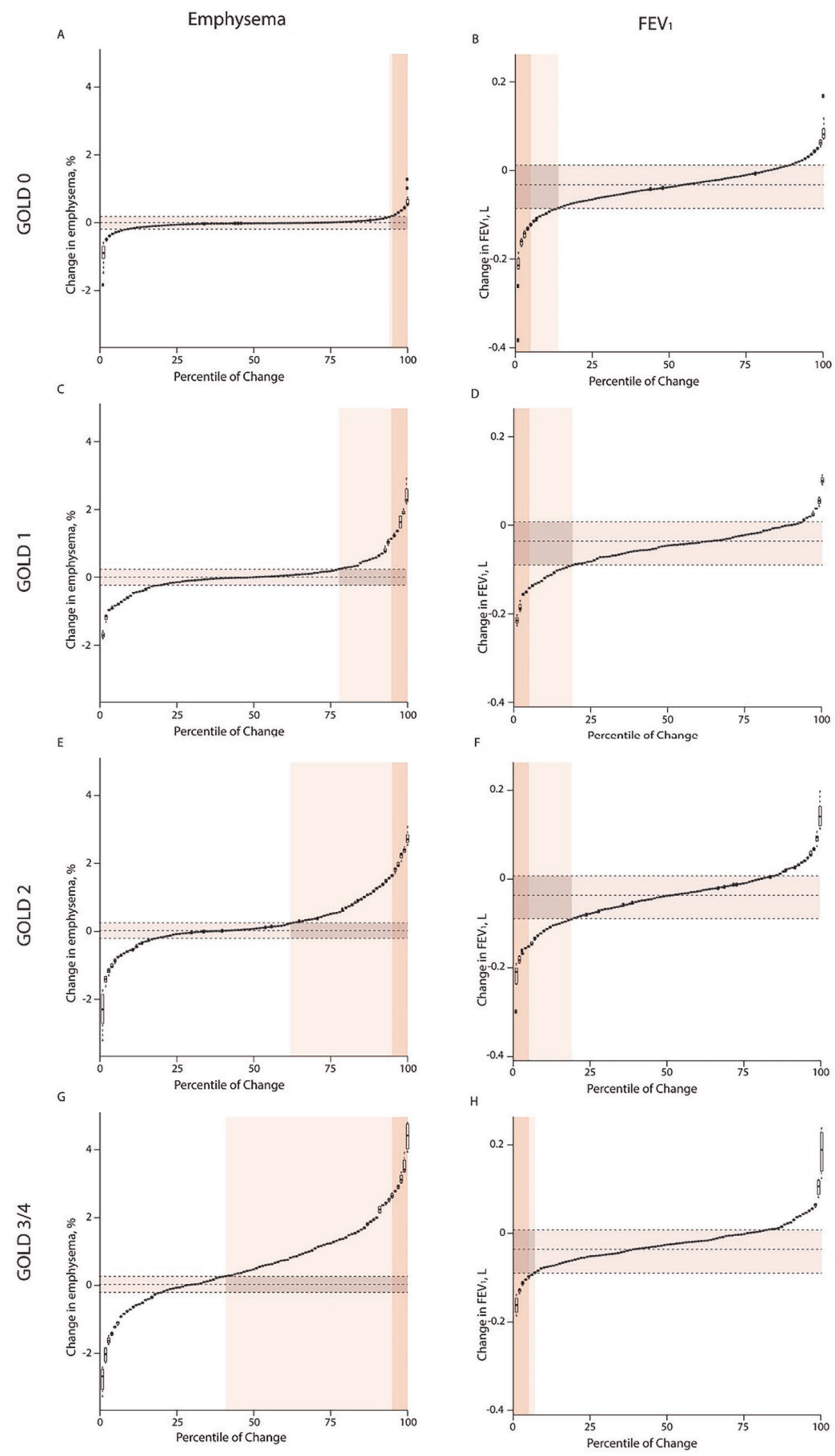

${ }^{a}$ rows

The gray area depicts the range between the 5th and 95th percentile of change in nonsmokers, based on which disease progression was defined. The light pink area denotes all participants who progressed beyond nonsmokers. The dark pink area denotes the $5 \%$ of participants who have the greatest progression. The proportion of participants progressing in emphysema increases with increasing GOLD stage, whereas the proportion of participants decreasing in FEV 1 is highest in GOLD 1 and GOLD 2.

GOLD=Global initiative for chronic Obstructive Lung Disease; FEV $V_{1}=$ forced expiratory volume in 1 second 


\section{Table 2. Number of Participants Showing Progression in Emphysema, Decrease in Forced Expiratory Volume in 1 Second or Both, Stratified by GOLD Spirometry Grade ${ }^{a}$}

\begin{tabular}{|c|c|c|c|c|}
\hline & $\begin{array}{c}\text { Progression in } \\
\text { Emphysema, } \\
\mathrm{n}(\%)\end{array}$ & $\begin{array}{l}\text { Decrease in } \\
\quad \mathrm{FEV}, \\
\mathrm{n}(\%)^{\mathrm{b}}\end{array}$ & $\begin{array}{l}\text { Change } \\
\text { in Both, } \\
n(\%)\end{array}$ & $\begin{array}{l}\text { Total Number of Participants with } \\
\text { Decrease in FEV }{ }_{1} \text { and/or } \\
\text { Progress of Emphysema, } n(\%)\end{array}$ \\
\hline GOLD $0(\mathrm{n}=1430)$ & $89(6.2 \%)$ & $186(13.2 \%)$ & $19(1.3 \%)$ & 256 (18.1\%) \\
\hline PRISm (n = 305) & $16(5.2 \%)$ & $22(7.4 \%)$ & $2(0.7 \%)$ & $36(12.0 \%)$ \\
\hline GOLD $1(\mathrm{n}=267)$ & $61(22.8 \%)$ & $50(19.0 \%)$ & 17 (6.4\%) & $94(35.7 \%)$ \\
\hline GOLD $2(n=616)$ & 235 (38.1\%) & $114(18.9 \%)$ & $58(9.5 \%)$ & $291(47.7 \%)$ \\
\hline GOLD 3/4 $(\mathrm{n}=398)$ & $238(59.8 \%)$ & $25(6.4 \%)$ & $19(4.8 \%)$ & 244 (61.6\%) \\
\hline
\end{tabular}

${ }^{a}$ Nonsmokers not included. Progression was defined as a 5-year increase in emphysema or a 5-year decrease in FEV 1 beyond nonsmoking participants $\left(0.25 \%\right.$ per year for emphysema and $89 \mathrm{~mL}$ per year for $\left.\mathrm{FEV}_{1}\right)$

balid percentage

GOLD $=$ Global initiative for chronic Obstructive Pulmonary Disease; FEV $1=$ forced expiratory volume in 1 second; PRISm=preserved ratio-impaired spirometry $\left(\mathrm{FEV}_{1}<80 \%\right.$ and $\left.\mathrm{FEV}_{1} / \mathrm{FVC} \geq 0.7\right)$

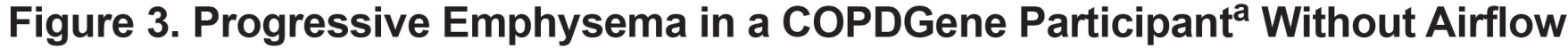 Limitation}
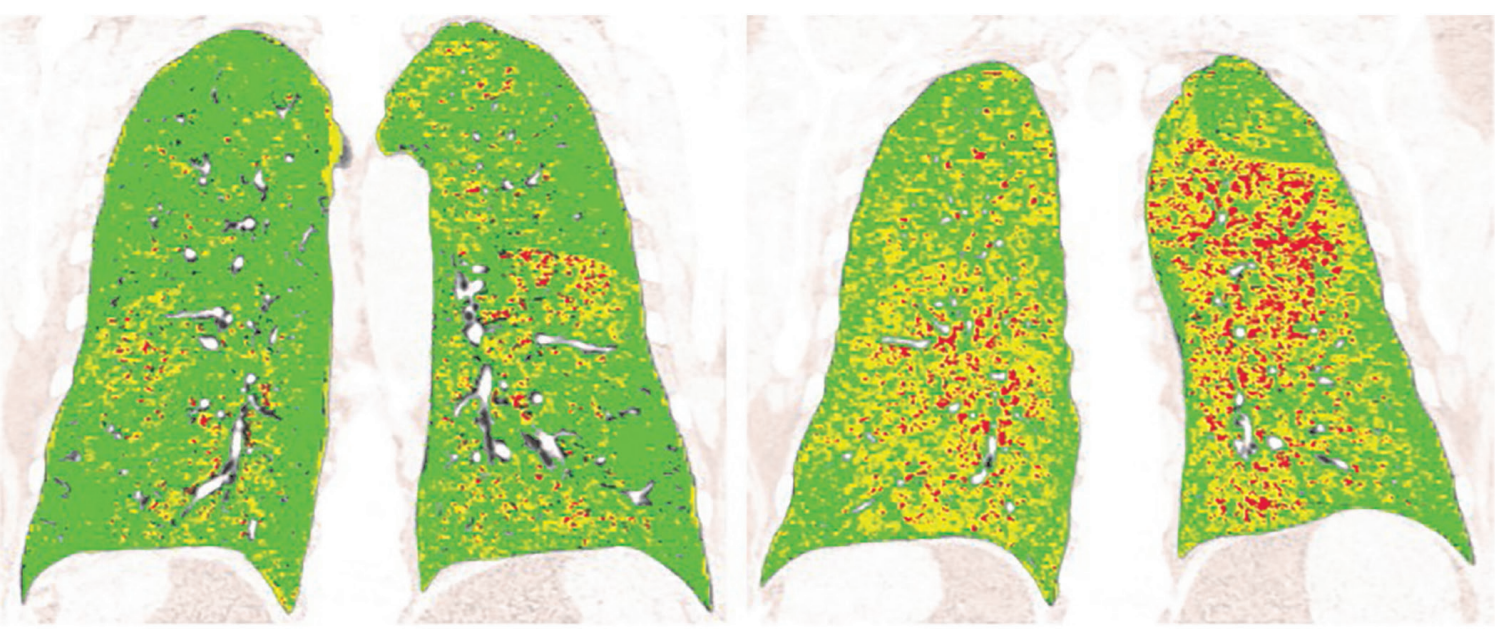

a53-year-old female

Baseline CT (left) showed mild emphysema (coded as red), and moderate air trapping (yellow). Follow-up CT at 5 years (right) shows substantial progression of air trapping and emphysema. Areas of air trapping have progressed to emphysema. FEV 1 decreased by only $200 \mathrm{ml}$ from $1.94 \mathrm{~L}$ to $1.59 \mathrm{~L}$. $\mathrm{FEV}_{1} / \mathrm{FVC}$ at baseline was $70 \%$ and decreased to $60 \%$.

COPDGene=COPD Genetic Epidemiology study; CT=computed tomography; FEV 1 =forced expiratory volume in 1 second; FVC=forced vital capacity

emphysema progression were lower baseline 6MWD (OR for $100 \mathrm{~m}$ increase: 0.99, 95\% CI 0.99 to 0.99) and higher baseline SGRQ (OR for 1-unit increase: 1.03 , 95\% CI 1.01 to 1.05). Baseline predictors of a decrease in FEV 1 were fSAD at baseline (OR for $1 \%$ increase: 1.05 , 95\% CI 1.01 to 1.09), the presence of emphysema (OR: 3.32 , $95 \%$ CI 1.49 to 4.59 ), and an increase in $\mathrm{mMRC}$ (OR for 1-unit increase: 1.35, 95\% CI 1.11 to 1.64 ).

\section{GOLD 2}

In GOLD 2 participants, the median (25th-75th percentile) percentage of emphysema at baseline was $2.9 \%(0.8-8.4)$. Median (25th-75th percentile) change 
Figure 4. Forest Plots of Odds of Emphysema Progression: Emphysema Present at Baseline Versus Emphysema Not Present at Baseline ${ }^{a}$

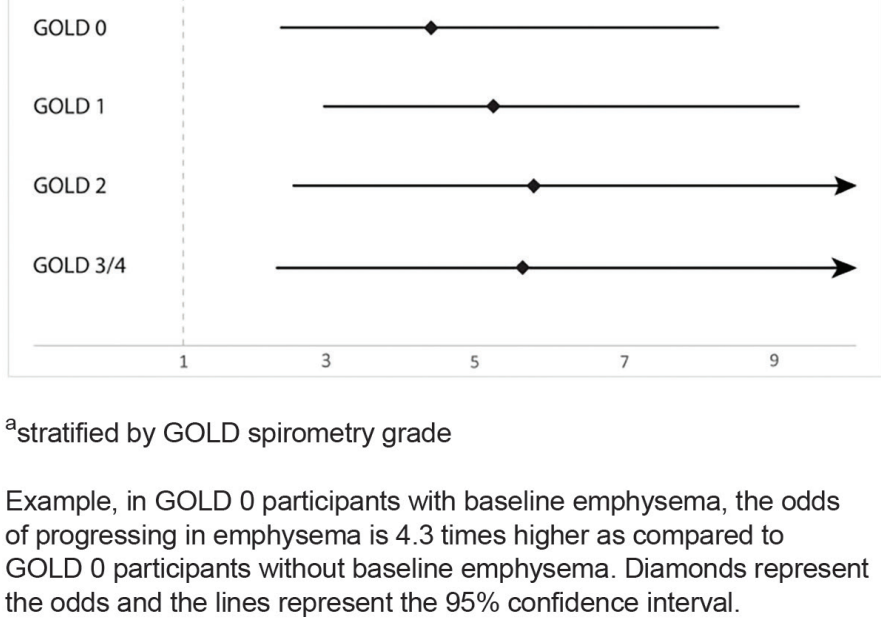

GOLD=Global initiative for chronic Obstructive Pulmonary Disease in emphysema per year was $0.08 \%(-0.08-0.54)$. Higher age and lower BMI were associated with a higher increase in emphysema over time ( $p=0.02$ and $p<0.001$, respectively).

Progression in emphysema occurred in 235/1430 (38.1\%) participants and decrease in FEV $\mathrm{F}_{1}$ occurred in 114 (18.5\%); progression in emphysema and decrease in $\mathrm{FEV}_{1}$ occurred in 58 (9.4\%) participants. The presence of emphysema at baseline was associated with higher odds of emphysema progression (OR: 5.69, $95 \%$ CI 2.48 to 13.06). Baseline fSAD was associated with emphysema progression as well (OR for $1 \%$ increase in fSAD: $1.04,95 \%$ CI: 1.01 to 1.06 ). Within the subgroup of participants with emphysema at baseline, $\mathrm{FSAD}$ was not associated with emphysema progression. Other clinical parameters were not associated with emphysema progression. Baseline predictors of a decrease in $\mathrm{FEV}_{1}$ were baseline $\mathrm{fSAD}$ (OR for $1 \%$ increase: $1.07,95 \%$ CI 1.05 to 1.08 ), baseline $\mathrm{ASAD}$ in the presence of emphysema (OR for $1 \%$ increase: $1.06,95 \%$ CI 1.04 to 1.08 ), and the presence of emphysema alone at baseline (OR:4.75, $95 \%$ CI 2.87 to 7.83$)$.

\section{Figure 5. Forest Plot of Odds of Progressing in Emphysema When Functional Small Airway Disease Increases by 1 Percent $^{a}$}

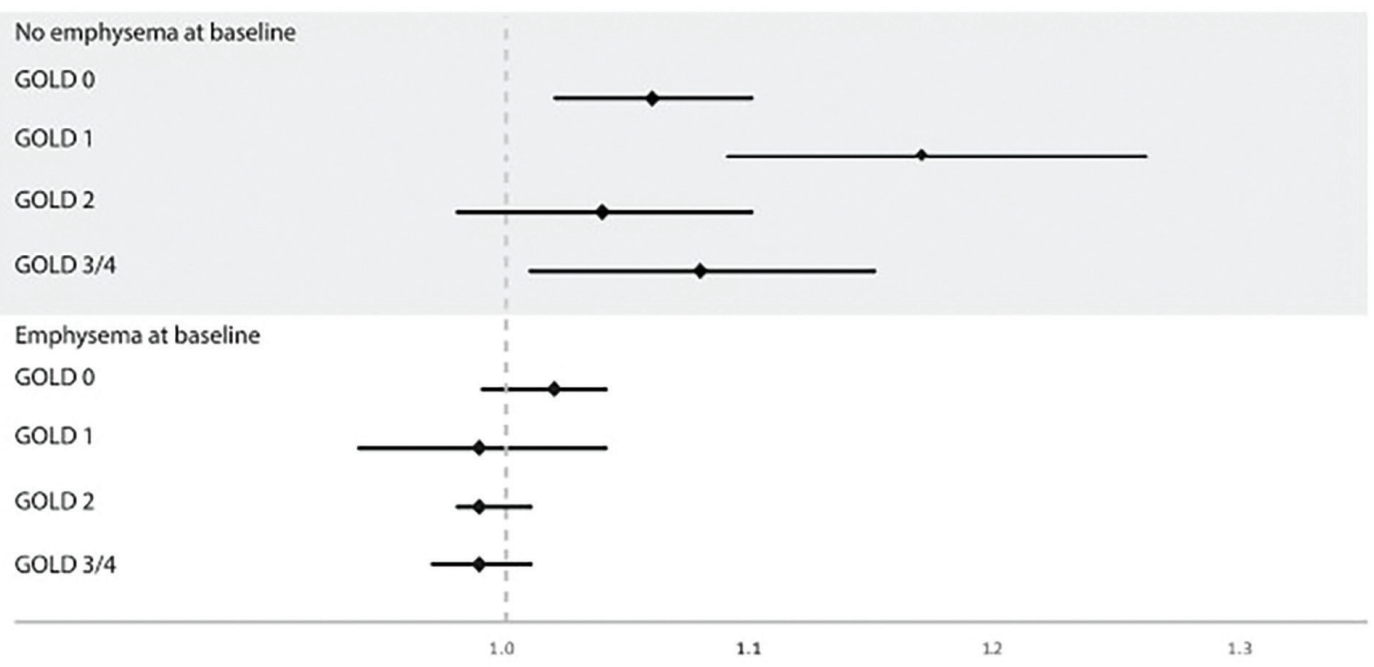

\footnotetext{
${ }^{a}$ stratified by the presence of baseline emphysema and GOLD spirometry grade

The association between $\mathrm{fSAD}$ and progression in emphysema was significant in GOLD 0, GOLD 1, and GOLD 3/4 participants without emphysema at baseline (gray area). For example, an increase of $1 \%$ in fSAD in GOLD 0 participants with no emphysema at baseline increased the odds of progression (odds ratio 1.06), but this effect was not significant when emphysema was present at baseline (white area). No associations were found in participants with GOLD 2. Diamonds represent the odds and the lines represent the $95 \%$ confidence interval.
} 


\section{GOLD $3 / 4$}

In GOLD 3/4 participants, the median (25th-75th percentile) amount of emphysema at baseline was 14.9\% (5.7-25.6). Median (25th-75th percentile) change in emphysema per year was $0.5 \%(-0.1-1.2)$. Lower BMI and more pack years were associated with a higher increase in emphysema over time $(p<0.001$ and $p=0.02$, respectively).

Progression in emphysema occurred in 238/1430 (59.8\%) participants; decrease in $\mathrm{FEV}_{1}$ occurred in 25 (6.3\%); progression in emphysema and decrease in $\mathrm{FEV}_{1}$ occurred in 19 (4.8\%) participants. The presence of baseline emphysema was significantly associated with emphysema progression (OR: 5.55, 95\%CI 2.26-13.58). fSAD at baseline was not associated with emphysema, but in the absence of baseline emphysema fSAD did associate with emphysema progression (OR for 1\% increase: 1.08, $95 \%$ CI 1.01-1.15). The presence of exacerbations was associated with emphysema progression as well (OR: 1.52, 95\%CI 1.09-2.11). The number of participants decreasing in $\mathrm{FEV}_{1}$ did not allow for multivariate comparisons.

\section{Sensitivity Analysis}

Sensitivity analyses using cut-off values at the 90th and 97.5 th percentile resulted in cut-off values of $0.14 \%$ and $0.45 \%$ emphysema per year, and $76 \mathrm{~mL}$ and $100 \mathrm{~mL}$ in $\mathrm{FEV}_{1}$ per year, respectively. In the model using the 90th percentile of change in emphysema some but not many associations were lost such as the association with $\mathrm{MMRC}$ in GOLD 0 , the association with FSAD in GOLD 1, the association with ISAD without baseline emphysema in GOLD 3/4, and the amount of exacerbations in GOLD 3/4 (Table S6). In the analysis using the 97.5 th percentile of change many associations with emphysema progression were similar, but the association with $\mathrm{SSAD}$ without baseline emphysema was lost in GOLD 0 and GOLD 3/4 (Table S7). For GOLD 0, this may be due to the reduced sample size of participants defined as progressing using the stricter 97.5 th percentile cutoff, as the magnitude of the association between emphysema progression and ISAD without baseline emphysema was similar.

In the model using the 90th percentile of change in $\mathrm{FEV}_{1}$ associations were found between fSAD, emphysema, and FEV 1 in GOLD 0 (Table S8). Using the 97.5th percentile of change in $\mathrm{FEV}_{1}$ resulted in losing the association with FSAD without emphysema in GOLD 2, but all other associations were similar to the 95th percentile of change (Table S9).

In the model using $\mathrm{FEV}_{1}$ decline of $10 \%$ from baseline ( $2 \%$ decrease in $\mathrm{FEV}_{1}$ per year), associations were found between $\mathrm{ASAD}$, emphysema, 6MWD, and SGRQ and FEV 1 progression in GOLD 0 and GOLD 2 that were not present in the 95th percentile model, but results were similar to the 90th percentile of change threshold of $76 \mathrm{~mL}$ per year. Using FEV decline of $20 \%$ to define progression, resulted in losing these associations. Complete results are shown in Supplementary Table S10 and S11. A list of robust parameters, significant in all sensitivity analyses, is shown in Table S12.

\section{Voxel Shifting}

The percentages of voxels that shift from one category to another are shown in Table S13 to Table S17. Results of these tables show that in GOLD 0 participants who progress in emphysema, $16.6 \%$ of normal voxels shift to fSAD voxels and $9.8 \%$ of fSAD voxels shift to emphysema voxels, compared to $5.6 \%$ and $0.2 \%$ in GOLD 0 participants that did not progress (both $p<0.001$ ). The same trend is seen in PRISm participants, GOLD 1 participants, and GOLD 3/4 participants.

\section{Discussion}

This study demonstrates that the presence of emphysema at baseline is strongly associated with emphysema progression, even when there is no airflow limitation at baseline. In addition, we found that fSAD was associated with emphysema progression, even in participants without baseline emphysema. Further, we showed that change in emphysema is not always accompanied by significant changes in $\mathrm{FEV}_{1}$ and may, therefore, represent relatively independent processes.

The most important finding of our study is that the presence of emphysema is associated with emphysema progression in all GOLD stages, even in individuals without COPD. This means that even at an early stage when there is no demonstrable spirometric deterioration, evaluating the presence of emphysema can identify individuals at risk of progression. Disease progression in GOLD 0 participants was mainly characterized by an increase in emphysema 
rather than spirometric deterioration, suggesting a limited role of spirometry in early disease.

A second relevant finding of this study is that in early disease (GOLD 0, PRISm, and GOLD 1), fSAD at baseline predicted the development of emphysema when no emphysema was present. This is in line with the hypothesis that small airways disease precedes emphysema and is consistent with the findings by Hogg et al using micro CT and magnetic resonance imaging. ${ }^{16}$ Indeed, when evaluating voxel-to-voxel shift, we found that in GOLD 0 participants progressing in emphysema, $9.8 \%$ of fSAD voxels shifted to emphysema versus $1.7 \%$ in participants who did not progress. The same trend was seen in GOLD 1 and PRISm. In addition, $16.6 \%$ of previously normal voxels progressed to fSAD in GOLD 0 participants who progressed in emphysema, suggesting that progressive emphysema is accompanied by progression of $\mathrm{fSAD}$. A similar analysis using this voxel-to-voxel shift was performed by Labaki et $\mathrm{al}^{7}$ in a subset of the COPDGene cohort where participants were only included when scanned on the same scanner make and model, and if there was $<15 \%$ difference in inspiratory lung volumes between baseline and follow-up (total $n=725$ ). They found that disease progression was mainly characterized by transition of normal or fSAD voxels to emphysema and showed that fSAD and emphysema are independent predictors of emphysema development. ${ }^{7}$ It is, however, important to realize that this represents a complex technique in which reproducibility is limited. Indeed, in this study, voxels being defined as "abnormal" (mainly fSAD) also shifted back to normal lung density. Nevertheless, the results of both studies are important for further research in the development of this disease with which early identification and preventative therapy could limit disease progression.

This study showed that in early disease, change in FEV 1 and emphysema overlapped only minimally and appear to be addressing different manifestations of disease in the early stages. Indeed, in a recent study performed by our group, ${ }^{17}$ we showed that progression in emphysema could only partly be explained by changes in FEV 1 . Airway disease has been shown to contribute substantially to airflow obstruction, ${ }^{18}$ and $\mathrm{FEV}_{1}$ deterioration is likely more pronounced when significant airway inflammation and/or destruction is present. This is in line with our finding of the predictive value of fSAD for lung function decline in GOLD 1 and GOLD 2 participants. Altogether, the results suggest that spirometry and imaging complement each other and can identify different elements of progression in chronic smoking-related lung disease.

We based our thresholds to identify both the presence and progression of emphysema on a group of non-smokers studied in the COPDGene cohort. Although this group was fairly small, it is the largest group of non-smokers with 5-year CT follow-up available. The threshold for the presence of baseline emphysema (>1.31\%) as defined with CT was comparable to earlier results from the NELSON trial, who found thresholds of $1.2 \%$ for current smokers and $1.7 \%$ for former smokers to be an appropriate cut-off. ${ }^{19}$ Progression in emphysema and decrease in $\mathrm{FEV}_{1}$ was defined using the 95th percentile of change in nonsmokers and thresholds that define progression resulted to be an increase of $0.25 \%$ emphysema per year and a decline of $89 \mathrm{~mL} \mathrm{FEV}$ 1 per year. Sensitivity analyses using the 90th and 97.5th percentile showed similar patterns of statistical significance meaning the results are robust to threshold choice. An increase of $0.25 \%$ emphysema per year may be subtle to be detected by CT, but it does highlight the effect of ageing on lung density. ${ }^{20,21}$

The mean decline of $31 \mathrm{ml}$ per year in $\mathrm{FEV}_{1}$ in nonsmokers in this study was comparable with other population-based studies and results are consistent with data from the Framingham Heart Study in which the upper limit of normal of lung function decline in 401 healthy adults was shown to be 101 $\mathrm{mL}$ per year over 4 years $(83 \mathrm{~mL}$ per year over 7 years in 354 participants). ${ }^{22}$ Although the results of sensitivity analyses were largely robust to the choice of threshold for defining progression, using the 90th percentile of change seen in non-smokers or a $10 \%$ decline from baseline to 5-year follow-up to define $\mathrm{FEV}_{1}$ progression (and, therefore, a slightly lower threshold) might be more appropriate as this resulted in more clinically significant associations especially in GOLD 0 and GOLD 2.

In studying participants at risk of progression, we provided information on the linear relationship between clinical variables, the percentage emphysema at baseline, and changes in emphysema over time. We confirmed that a higher age, male gender, nonHispanic white race, and current smoking were associated with higher emphysema in almost all 
GOLD stages. ${ }^{23-26}$ We found that in participants without COPD, males have higher emphysema at baseline and they progress faster with $0.3 \%$ more per year as compared to females. Also, in participants with GOLD 2 to 4, lower BMI played a role in emphysema progression, which is in line with results from Bhavani et al. ${ }^{27}$ In addition, more pack years were associated with higher baseline emphysema in GOLD 1 and GOLD 2, but not in the other GOLD stages. In participants without spirometric COPD and in participants with severe COPD (GOLD 3 and GOLD 4), smoking status seemed to predominate.

A few limitations need to be addressed. First, the multi-center design of the study introduced possible sources of variability, including differences in CT scanner make and model. This was addressed by including study center in the analysis, however, the measurements could still be vulnerable to other sources of noise. ${ }^{28,29}$ Although FRC/TLC was included in the linear multivariate analyses to correct for changes in inspiration and expiration level, it could be more desirable to have spirometric control or to include plethysmographic data. Second, expiratory CT measurements would ideally be measured at residual volume which is more traditionally used to assess small airway disease. However, expiration to functional residual capacity is thought to be more reproducible, and previous work has shown that parametric response-mapping metrics obtained using this technique correlate well with other functional measurements and predict decline in $\mathrm{FEV}_{1}$. 6,30 Third, this analysis was limited to the first 5000 COPDGene participants who returned for a 5-year follow-up and who had acceptable CT studies. A selection bias may have been introduced due to loss of participants from illness or death. The absence of these ill or deceased participants may have reduced the signal for disease progression in this study, particularly in those with more advanced disease.

It has been shown that in current and former smokers who do not meet a spirometric definition of COPD, lung abnormalities as well as clinical impairments are common, ${ }^{2}$ but data was lacking on how to identify those who are at risk for disease progression. As emphysema is associated with increased mortality, it is important to identify those individuals who are vulnerable to cigarette smoke. ${ }^{31}$ We concluded that CT-derived emphysema and ISAD are both important in identifying individuals prone to develop progressive emphysema, which supports the potential role of quantitative CT in heavy smokers.

\section{Acknowledgements}

The project described was supported by grants R01HL089897 and R01HL089856 from the National Heart, Lung, and Blood Institute. The COPDGene project is also supported by the COPD Foundation through contributions made to an industry advisory board representing AstraZeneca, Boehringer Ingelheim, Novartis, Pfizer, Siemens, Sunovion, and GlaxoSmithKline. In addition, this project has been financially supported by the Foundation "De Drie Lichten" in the Netherlands, the Lung Foundation Netherlands (grant 9.1.15.067FE), and the Foundation "Stichting Astma Bestrijding".

Author Contributions: Study conception and design was provided by EP, CMM, JDC, EAR, and DAL. Data analysis and interpretation was provided by EP, CMM, JDC, EAR, MJS. DAL EP, CMM, FAAMH. PAdJ, J-PC, $\mathrm{MKH}, \mathrm{SMH}, \mathrm{CRH}, \mathrm{CJ}, \mathrm{EKS}, \mathrm{JDC}, \mathrm{GRW}, \mathrm{EAR}, \mathrm{BM}$, MJS, J-WJL, EMvR, and DA drafted the manuscript for important intellectual content.

\section{Declaration of Interest}

E Pompe reports personal fees from Thirona BV outside the submitted work. JP Charbonnier reports personal fees from Thirona BV, during the conduct of the study. MK Han reports personal fees from GSK, Boehringer Ingelheim, AstraZeneca, and Novartis, outside the submitted work. SM Humphries reports grants from the National Heart, Lung, and Blood Institute, during the conduct of the study. CR Hatt is a salaried employee of Imbio, LLC. CJ Galbán reports grants from the National Institutes of Health, during the conduct of the study. He has a patent for the Voxelbased analysis of registered medical images acquired from multiple phases with royalties paid to Imbio. EK Silverman reports grants from the National Institutes of Health and grants and other expense payments from the COPD Foundation, during the conduct of the study. In addition, he reports personal fees from GSK, Merck, and other expense payments from Novartis, outside the submitted work. GR Washko reports support from GSK, PulmonX, and Boehringer Ingelheim, outside the submitted work. B Make reports support from Novartis for research for this study, medical advisory boards for Forest, Spiration, 
AstraZeneca, Boehringer-Ingelheim, CSL Bering, GSK, Novartis, Sunovian, Theravance, and Verona. In addition, he received research grants, controlled by National Jewish Health, from AstraZeneca, Boehringer-Ingelheim, Forest, GSK, Pearl, Sunovian, and the National Heart, Lung, and Blood Institute and he provided continuing medical education for the American College of Chest Physicians, the Cleveland Clinic, Consensus Medical Education, Hybrid Communications, Integrity Medical Education, Mt. Sinai Medical Center, WebMD, the Foundation for Improving Patient Outcome, Medscape, National Jewish Health, the Peer Review Institute, and SPIRE Learning. He also receives royalties from Up-ToDate, the Data Safety Monitoring Board for Spiration, the National Heart, Lung, and Blood Institute, and Baxalta. MJ Strand reports grants from the National Heart, Lung, and Blood Institute, during the conduct of the study. J-WJ Lammers reports grants from TiPharma and EU, during the conduct of the study. EM van Rikxoort is co-founder and a shareholder of Thirona BV. DA Lynch reports grants from the National Heart, Lung and Blood Institute, during the conduct of the study, personal fees from Parexel, support from Veracyte, and personal fees from Boehringer Ingelheim and Genentech/Roche, outside the submitted work. CM Moore, FAA Mohamed Hoesein, PA de Jong, JD Crapo, and EA Regan, have nothing to disclose. 


\section{References}

1. 1. Løkke A, Lange P, Scharling H, Fabricius P, Vestbo J. Developing COPD: a 25 year follow up study of the general population. Thorax. 2006;61(11):935-939.

doi: https://doi.org/10.1136/thx.2006.062802

2. Regan EA, Lynch DA, Curran-Everett, et al. Clinical and radiologic disease in smokers with normal spirometry. JAMA Intern Med. 2015;175(9):1539-1549.

doi: https://doi.org/10.1001/jamainternmed.2015.2735

3. Woodruff PG, Barr RG, Bleecker E, et al. Clinical significance of symptoms in smokers with preserved pulmonary function. $N$ Engl $J$ Med. 2016;374:1811-1821.

doi: https://doi.org/10.1056/NEJMoa1505971

4. Mets OM, Buckens CF, Zanen P, et al. Identification of chronic obstructive pulmonary disease in lung cancer screening computed tomographic scans. JAMA.2011;306(16):1775-1781.

doi: https://doi.org/10.1001/jama.2011.1531

5. Mets OM, Schmidt M, Buckens $\mathrm{CF}$, et al. Diagnosis of chronic obstructive pulmonary disease in lung cancer screening computed tomography scans: independent contribution of emphysema, air trapping, and bronchial wall thickening. Resp Res. 2013;14:59. doi: https://doi.org/10.1186/1465-9921-14-59

6. Bhatt SP, Soler X, Wang X, et al. Association between functional small airways disease and $\mathrm{FEV}_{1}$ decline in COPD. Am $J$ Respir Crit Care Med. 2016;194(2):178-184.

doi: https://doi.org/10.1164/rccm.201511-2219OC

7. Labaki WW, Gu T, Murray S, et al. Voxel-wise longitudinal parametric response mapping analysis of chest computed tomography in smokers. Acad Radiol. 2019;26(2):217-223. doi: https://doi.org/10.1016/j.acra.2018.05.024

8. Regan EA, Hokanson JE, Murphy JR, et al. Genetic Epidemiology of COPD (COPDGene) study design. COPD. 2010;7(1):32-43. doi: https://doi.org/10.3109/15412550903499522

9. Wan ES, Castaldi PJ, Hokanson JE, et al. Epidemiology, genetics, and subtyping of preserved ratio impaired spirometry (PRISm) in COPDGene. Respir Res. 2014;15:89.

doi: https://doi.org/10.1186/s12931-014-0089-y

10. Global Initiative for Chronic Obstructive Lung Disease (GOLD). Global strategy for the diagnosis, management, and prevention of chronic obstructive pulmonary disease, 2020 report. GOLD website. Published December 2019. Accessed February 2020. http:// goldcopd.org.

11. Jones PW, Quirk FH, Baveystock CM, Littlejohns P. A self-complete measure of health status for chronic airflow limitation. The St George's Respiratory Questionnaire. Am Rev Respir Dis. 1992;145(6):13211327. doi: https://doi.org/10.1164/ajrccm/145.6.1321

12. Mahler DA, Wells CK. Evaluation of clinical methods for rating dyspnea. Chest. 1988;93(3):580-586.

doi: https://doi.org/10.1378/chest.93.3.580
13. Van Rikxoort EM, de Hoop B, Viergever MA, Prokop M, van Ginneken. Automatic lung segmentation from thoracic computed tomography scans using a hybrid approach with error detection. Med Phys. 2009;36:2934-2947.

doi: https://doi.org/10.1118/1.3147146

14. Galbán CJ, Han MK, Boes JL, et al. Computed tomographybased biomarker provides unique signature for diagnosis of COPD phenotypes and disease progression. Nat Med. 2012;18(11):17111715. doi: https://doi.org/10.1038/nm.2971

15. Boes JL, Hoff BA, Bule M, et al. Parametric response mapping monitors temporal changes on lung CT scans in the subpopulations and intermediate outcome measures in COPD study (SPIROMICS). Acad Radiol. 2015;22(2):186-194.

doi: https://doi.org/10.1016/j.acra.2014.08.015

16. Hogg JC, McDonough JE, Suzuki M. Small airway obstruction in COPD: new insights based on Micro-CT imaging and MRI imaging. Chest. 2013;143(5):1436-1443.

doi: https://doi.org/10.1378/chest.12-1766

17. Pompe E, Strand M, van Rikxoort EM, et al. Five-year progression of emphysema and air trapping at CT in smokers with and those without chronic obstructive pulmonary disease: results from the COPDGene study. Radiology. 2020;295(1):218-226.

doi: https://doi.org/10.1148/radiol.2020191429

18. Hogg JC, Chu F, Utokaparch S, et al. The nature of small-airway obstruction in chronic obstructive pulmonary disease. $N$ Engl J Med. 2004;350:2646-2653.

doi: https://doi.org/10.1056/NEJMoa032158

19. Mohamed Hoesein FAA, Schmidt M, Mets OM, et al. Discriminating dominant computed tomography phenotypes in smokers without or with mild COPD. Resp Med. 2014;108:136-143.

doi: https://doi.org/10.1016/j.rmed.2013.08.014

20. Copley S, Giannarou S, Schmid V, Hansell D, Wells A, Yang G-Z. Effect of aging on lung structure in vivo: assessment with densitometric and fractal analysis of high-resolution computed tomography data. $J$ Thorac Imaging. 2012;27(6):366-371.

doi: https://doi.org/10.1097/RTI.0b013e31825148c9

21. Boudewijn IM, Postma DS, Telenga ED, et al. Effects of ageing and smoking on pulmonary computed tomography scans using parametric response mapping. Eur Med J Resp. 2015;46:1193-1196. doi: https://doi.org/10.1183/09031936.00009415

22. Kretschman D, Gao W, Dupuis J, Latourelle J, O’Connor G. Rate of $\mathrm{FEV}_{1}$ decline in healthy adults: defining the upper limit of normal in the Framingham Heart Study. Am J Respir Crit Care Med. 2012;185:A2056.

doi: https://doi.org/10.1164/ajrccm-conference.2012.185.1_Meeting Abstracts.A2056

23. Hardin M, Foreman M, et al. Sex-specific features of emphysema among current and former smokers with COPD. Eur Respir J. 2016;47(1):104-112.

doi: https://doi.org/10.1183/13993003.00996-2015 
24. Hansel NN, Washko GR, Foreman MG, et al. Racial differences in CT phenotypes in COPD. COPD. 2013;10(1):20-27.

doi: https://doi.org/ 10.3109/15412555.2012.727921

25. Coxson HO, Dirksen A, Edwards LD, et al. The presence and progression of emphysema in COPD as determined by CT scanning and biomarkers expression: a prospective analysis from the ECLIPSE study. Thorax. 2013;1(2):129-136. doi: https://doi.org/10.1016/S2213-2600(13)70006-7

26. Mohamed Hoesein FAA, Zanen P, de Jong PA, et al. Rate of progression of CT-quantified emphysema in male current and ex-smokers: a follow-up study. Resp Res. 2013;14:55.

doi: https://doi.org/10.1186/1465-9921-14-55

27. Bhavani S, Tsai C-L, Perusich S, et al. Clinical and immunological factors in emphysema progression. Five-year prospective longitudinal exacerbation study of chronic obstruction pulmonary disease (LESCOPD). Am J Respir Crit Care Med. 2015;192(10):1171-1178. doi: https://doi.org/10.1164/rccm.201504-0736OC

28. Boes JL, Bule M, Hoff BA, et al. The impact of sources of variability on parametric response mapping of lung CT scans. Tomography. 2015;20(1 Suppl):1-26.

doi: https://doi.org/10.18383/j.tom.2015.00148

29. Zach JA, Newell JD Jr, Schroeder J, et al. Quantitative computed tomography of the lungs and airways in healthy nonsmoking adults. Invest Radiol. 2012;47(10):596-602.

doi: https://doi.org/10.1097/RLI.0b013e318262292e

30. Criner RN, Hatt CR, Galbán CJ, et al. Relationship between diffusion capacity and small airway abnormality in COPDGene. Respir Res. 2019;20(1):269.

doi: https://doi.org/10.1186/s12931-019-1237-1

31. Han MK. Clinical correlations of computed tomography imaging in chronic obstructive pulmonary disease. Annal Am Thorac Soc. 2013;10 (Suppl):S131-137.

doi: https://doi.org/10.1513/AnnalsATS.201303-046AW 